\title{
Associations between lifestyle, physical and social environments and frailty among Chinese older people: a multilevel analysis
}

Bo Ye ${ }^{1}$, Junling $\mathrm{GaO}^{1}$ and Hua Fu${ }^{2^{*}}$

\begin{abstract}
Background: Frailty represents a public health priority and an increasingly prevalent condition in the ageing population. It is seen as reflecting an interaction among individual factors and a range of environmental elements. This study aims to examine the association between frailty and individual factors, physical and social environments among Chinese older people.
\end{abstract}

Methods: The data were from the Shanghai Healthy City Survey in 2017, which sampled 2559 older people aged $\geq 60$ years from 67 neighbourhoods. The FRAlL scale was used to assess frailty, and social and physical environments were assessed using validated and psychometrically tested instruments. Individual factors included age, gender, education, employment, marital status, smoking, drinking, physical exercise, organization participation, self-rated health and psychological well-being. A multilevel analysis was conducted to examine whether physical and social environments were associated with frailty.

Results: The prevalence of pre-frailty and frailty were 39.5 and $16.9 \%$, respectively. The prevalence of frailty increased with age from $14.6 \%$ (60-64 years) to $26.5 \%$ ( $\geq 75$ years). After adjusting for age and/or gender, older age, women, and those with low education, alcohol dependence, physical inactivity, poor self-rated health, or psychological disorders had a higher prevalence of frailty. The multilevel analysis indicated that after controlling for individual covariates, compared to the 1st quartile of aesthetic quality, the odds ratio (OR) of frailty for the 4th quartile was 0.65 (0.47-0.89); compared to the 1st quartile of walking environment, the OR of frailty for the 4th quartile was 0.43 (0.19-0.95); compared to the 1st quartile of social cohesion, the OR of frailty for the 4th quartile was 0.73 (0.54-0.99); compared to the 1st quartile of social participation, the ORs of frailty for the $2 \mathrm{nd}$, 3rd and 4th quartiles were $0.76(0.59-0.97), 0.59(0.45-0.77)$ and $0.59(0.45-0.77)$, respectively.

Conclusions: Frailty is a highly prevalent health condition among the aged population in China. Healthcare should focus on frail elderly who are older age, women, those with low education, and those with mental health problems. It may decrease frailty among Chinese older people to encourage social participation and healthy behaviours and to build aesthetic, walkable and cohesive neighbourhoods.

Keywords: Frailty, Lifestyle, Physical environment, Social environment, Multilevel modelling

\footnotetext{
* Correspondence: hfu@fudan.edu.cn

${ }^{2}$ Fudan Health Communication Institute, School of Public Health, Fudan

University, PO Box 248, 138 Yixueyuan Road, Shanghai 200032, China

Full list of author information is available at the end of the article
}

(c) The Author(s). 2018 Open Access This article is distributed under the terms of the Creative Commons Attribution 4.0 International License (http://creativecommons.org/licenses/by/4.0/), which permits unrestricted use, distribution, and reproduction in any medium, provided you give appropriate credit to the original author(s) and the source, provide a link to the Creative Commons license, and indicate if changes were made. The Creative Commons Public Domain Dedication waiver (http://creativecommons.org/publicdomain/zero/1.0/) applies to the data made available in this article, unless otherwise stated. 


\section{Background}

Frailty increases an individual's vulnerability to increased dependency and death [1]. Numerous studies have shown that frailty often leads to a higher risk of worsening disability, falls, hospital admissions, and mortality [2]. The prevalence of frailty among community-dwelling older people in the Asia-Pacific region is approximately 3.5$27 \%$, which is comparable to the prevalence across Europe and the Americas [3, 4]. Frailty increases with age [5], it represents a public health priority for multiple reasons, and it is a highly and increasingly prevalent condition in the ageing population [4]. Importantly, frailty may be even more prevalent in low- and middle-income countries [6]. Thus, the frailty among older people in China, which is a developing country with the largest and most rapidly growing ageing population, would be a more serious and urgent public health issue.

A large amount of evidence shows that multiple aetiologic factors, including cumulative cellular damage, malnutrition, sarcopenia, and inflammation, contribute to frailty [7]. Exercise and appropriate nutrition are first-line treatments for frailty [2]. From a public health perspective, lifestyle and healthy behaviours such as physical activity and a healthy diet seem to play important roles in preventing frailty. Previous studies also indicated that physical inactivity and alcohol use were positively related to frailty $[8,9]$. Other factors linked with frailty development include socio-demographic characteristics, such as poverty, educational level and marital status [8-10]. One previous study indicated older people who participated in organizations had a lower risk of functional disability [11]. Moreover, the lifestyle of older people are probably affected by neighbourhood environments where they live. For example, transportation, social activities and healthy diet behaviours were proved to be related to neighbourhood walkability and aesthetics [12, 13]. It is important to understand the associations between lifestyle and frailty in the local context.

According to theories of environmental gerontology, over their life span, people are influenced by an ongoing interchange between the individual and their social and physical environment [14]. Frailty is seen as reflecting an interaction among individual factors and a range of environmental elements [15]. Recently, the WHO proposed a new goal about healthy ageing, which redefines the process of developing and maintaining the functional ability that enables well-being in older age [6]. It highlights the influence of intrinsic capacity and the relevant environment. Frailty is a complex health issue and commonly known as a geriatric syndrome [16]. It is not just the result of a decline in intrinsic capacity but is more affected by the living environment. For example, those who have declined mobility would be most limited by not having walkable roads or accessible facilities or emotional and practical support, then would become frail, in a vicious circle. Increasing physical activity has been showed to be an effective intervention for frail elderly people [17]; meanwhile, physical activity is most influenced by the neighbourhood environment. It is reasonable to believe that the living environment plays an important role in the transformation of frailty status. Especially for many older people, the neighbourhood of residence represents their predominant environmental context.

In recent years, China has been undergoing a rapid transition from a rural to an urban society, meanwhile facing the largest and the most rapidly growing ageing population in the world [18]. Shanghai is one of the most rapidly ageing cities in China, with $14.3 \%$ of the population being older adults aged 65 and above, and the proportion is expected to increase to nearly $20 \%$ by 2030 [19]. Great changes have taken place in Shanghai's construction, such as rural relocation and community reconstruction. The physical environment of community has changed, and some people from different areas have moved into new communities. The environmental characteristics of neighbourhood are more important to older people who are likely to be spending more time with neighbours in their immediate neighbourhood [20]. However, there are few studies on physical environment and frailty. Most studies focus on the relationships between physical environment and behaviours and/or well-being among older people [21-23]. The social environment is also important for preventing or reducing frailty, and different dimensions of the social environment have different effects [24]. However, the correlation between frailty and the dimensions of the social environment, such as social support and social network are discovered inconsistent results [24]. Another study indicated that social cohesion, neighbourhood belonging and feeling secure were protective factors against frailty [25]. We believe it is necessary to examine the relationships between physical and social neighbourhood environments and frailty based on the rare evidence that has been presented.

The aims of the present study were: 1) to examine the individual-level socio-demographic, lifestyle, and health condition correlates of frailty; and 2) to examine the relationships between individual- and neighbourhood-level physical and social environments with frailty among Chinese older people.

\section{Methods}

\section{Participants and study design}

In shanghai, 8089 community-living residents were recruited in the Shanghai Healthy City Survey (Round 5) from June to September 2017 using a multistage stratified 
random sampling method. First, we used stratified random sampling to select neighbourhoods/villages in each district. Second, we used simple random sampling to select residents' addresses in each selected neighbourhood/ village. Lastly, the trained health-related workers from each selected neighbourhood/village committee visited the addresses and interviewed residents using uniform questionnaires after obtaining the informed consent in person. In addition, if there was no respondent in the house after two visits or the worker was rejected, we could investigate their neighbours. Inclusion criteria were: 1) live at the address for more than half a year; 2) age 15 years and older; and 3) birthday is closer to the survey date. Exclusion criteria were: 1) severe psychological disorders; and 2) inability to answer questions. The Ethics Committee for Medical Research at the School of Public Health, Fudan University approved the study.

We used a sub-sample $(2846 / 8089,35.2 \%)$ of subjects who were 60 years of age or older. In Shanghai, the neighbourhoods were clustered administratively. Specifically, every sub-district of a city's district administers many neighbourhoods. Each neighbourhood has a committee to administer the residents living in that neighbourhood [26]. In total, 2559 (89.9\%) older people were sampled from 67 neighbourhoods (mean $=38$ elders; range: 2-104 elders) after excluding the incomplete data (Additional file 1: Sheet 1).

\section{Measurements \\ Frailty}

The FRAIL scale was used to measure frailty. It consists of 5 items (Fatigue, Resistance, Ambulation, Illness, and Loss of weight) from both the Frailty Index (FI) and Freid's Frailty Phenotype (FP) [27]. The FRAIL scale was a brief and valid tool that could effectively identify frailty/pre-frailty status, as well as had a strong ability to predict mortality risk [28]. Meanwhile, a previous study showed that the FRAIL scale could be used by non-healthcare professionals as a community screening tool for frailty among Chinese older people [29]. Frailty scores range from 0 to 5 (i.e., 1 point for each component; $0=$ best to $5=$ worst) and represent frail (3-5), pre-frail (1-2), and robust (0) health status.

\section{Environmental characteristics Physical environment}

Two physical characteristics of neighbourhood were included in our study. One of the physical characteristics of neighbourhood is aesthetic quality (AQ), which consists of 5 items with item 1 and item 2 being reverse coded. The other physical characteristics of neighbourhood is walking environment (WE), which consists of 7 items. All response categories were 'strongly disagree', 'disagree,' 'neutral,' 'agree', and 'strongly agree' on a scale of 1 to 5. Mujahid et al. [30] developed the original scale, and the Chinese version was revised and validated [23]. Cronbach's alpha of the two scales were 0.75 and 0.91 for the current sample, respectively.

\section{Social environment}

Two social characteristics of neighbourhood were also included. One of social characteristics of neighbourhood is social cohesion (SC), which comes from Mujahid et al. [30], and consists of 4 items. Each item also was assessed using a five-point Likert scale, ranging from 'strongly disagree' (1) to 'strongly agree' (5). The other social characteristics of neighbourhood is social participation (SP), which was developed by Gao et al. and was validated in Chinese populations [22, 23]. The scale is assessed by asking respondents how often in the past 12 months did you participate in the eight types of social activities (see Table 1). The answer for each social activity were 'never', 'several times per year', 'several times per month', 'once per week', and 'two or more times per week' on a scale of 1 to 5 . Cronbach's alpha of the two scales were 0.91 and 0.84 for the current sample, respectively.

The mean score of individual's assessment on each scale's items represented individual-level environmental characteristic. Due to different individuals having varying perceptions of the same reality, using the average of the responses across multiple persons within a neighbourhood reduces measurement error $[23,30]$. Therefore, the mean score of all respondents in the same neighbourhood for each scale was used to estimate the neighbourhood-level environmental characteristics. However, there was a limitation that some neighbourhoods only included very small samples [30]. For that reason, we excluded the neighbourhoods with fewer than 30 samples in the multilevel model. Finally, a sample of 2154 (84.2\%) elders from 42 neighbourhoods (mean $=51$; range: $30-104$ ) was included in multilevel model (Additional file 1: Sheet 2). For analyses, we transformed the mean scores of environmental characteristics into quartiles, with the first quartile indicating the lowest level of environmental characteristics.

Table 1 The eight types of social activities for measuring social participation (SP)

1) visiting family or friends

2) recreational activities involving other people

3) physical and cultural activities in the neighbourhood

4) attending a series of lectures in the neighbourhood

5) a self-management group or mutual-help group

6) volunteer or charity work

7) activities of political organizations or associations

8) dining out or shopping with other people 


\section{Individual characteristics}

Demographic Demographics included age (age groups were divided into $60-64$ years, $65-69$ years, $70-74$ years, and $\geq 75$ years), gender (men and women), educational level (illiteracy, primary school, junior high school, senior high school, and university), marital status (married and other, which included divorced, widowed and unmarried), work status (employed and other, which included retired and unemployed).

Lifestyle Individual lifestyles included smoking, alcohol consumption, moderate intensity physical activity (MIPA), and organization participation. Smoking status was divided into nonsmoker, ex-smoker, and current smoker. Alcohol consumption was divided into 3 categories: nondrinker, drinker, and alcohol dependence. Alcohol dependence was assessed using the CAGE (Cut down, Annoyed, Guilty, Eye opener) questionnaire [31]. The CAGE questionnaire contains 4 items, and a two-item positive response was considered as alcohol dependence in our study. MIPA was assessed using two questions: "Q1. How many times did you participate in moderate intensity physical activity (heart rate and breathing rate increase and slight perspiration) per week? (none, 1-2 times, 3-4 times, 5-6 times, 7 times or more); Q2. How long did you participate every time? (less than $20 \mathrm{~min}, 20-30 \mathrm{~min}, 30-40 \mathrm{~min}, 40-50 \mathrm{~min}$, or more than $50 \mathrm{~min}$ )." MIPA was also divided into 3 categories: none, low, and high. Those who answered "none" for Q1 were classified as none; those who answered "3-4 times" or more for Q1 and "30-40 min" or more for Q2 were classified as high; those who answered less than "3-4 times" for Q1 or less than "30-40 min" for Q2 were classified as low. Organization participation was assessed by asking respondents if they participated in six types of organizations: 1) interest activity group (e.g., senior university, senior centre), 2) volunteer organization, 3) government departments (e.g., neighbourhood committees, street offices), 4) party grouping (e.g., party branch, other democratic parties), 5) work-related organization (e.g., worker union, commission of retirees, trade association), or 6) religious organization. Those who participated in any one of these organizations were classified as reporting organization participation (yes), and those who did not participate in any organizations were classified as not reporting organization participation (no).

\section{Health condition}

Health conditions included self-rated health (SRH) and psychological well-being (PWB). SRH was assessed by a single question: "Would you say that in general your health is excellent, very good, good, fair, or poor?" From this question, we classified the answer as a binary variable $(0=$ poor, included fair or poor; $1=$ good, included excellent, very good, and good). PWB was assessed using a Chinese version of the World Health Organization Well-Being Index (WHO-5), the total score ranges from 0 to 25 , and the higher score means a better quality of life. Those who scored lower than 13 or had a score 0 or 1 on any one of 5 items were considered as having a psychological disorder [32].

\section{Statistical analysis}

First, we used descriptive analysis and a $X^{2}$ trend test to show the prevalence of frailty by gender and age groups.

Second, we used analysis of variance (ANOVA) for continuous variables and $x^{2}$ test for categorical variables to compare the difference in the prevalence of frailty between groups (robust, pre-frail, frail). Then, an ordinal logistic regression analysis was performed to examine the associations between individual demographics, lifestyle, health conditions (independent variables) and frailty (dependent variable) adjusted for gender and/or age (control variable).

Third, we used a multilevel analysis to explain the relationship between environmental characteristics and frailty. Our final data included 42 neighbourhoods and 2154 elders living in these neighbourhoods. As the individuals (level 1) are nested in neighbourhoods (level 2), a multilevel analytic approach was adopted. We fitted the data using a multilevel mixed-effects ordered logistic regression model, controlling for both individual-level and neighbourhood-level variables as fixed effects and allowing for a random intercept for frailty. After examining the neighbourhood-level variance in frailty without adding any explanatory variables (null model), we successively examined the association between individual-level and neighbourhood-level environmental characteristics and frailty. Then, with controlling for individual covariates, both individual- and neighbourhood-level environmental variables were added to the final model. We estimated the adjusted ORs and their $95 \%$ confidence intervals (CIs) of environmental variables for frailty and used $-2 \log$ likelihood (-2LL) and Akaike information criterion (AIC) to compare the goodness-of-fit of each model. The windows-based SPSS version 22.0 (SPSS Inc., Chicago, IL, USA) was used for the descriptive analysis, univariate analysis and logistic regression analysis, and Stata version 14.1 (StataCorp, Texas, USA) was used for the multilevel analysis. A $P$ value less than 0.05 was considered statistically significant for all statistical analyses.

\section{Results}

Prevalence of frailty by age and gender

Two thousand five hundred and fifty-nine community residents aged 60 years and older were incorporated into the final sample. The mean age of total elders was 
$(66.12 \pm 4.85)$ years; $42.6 \%(n=1089)$ were men and $57.4 \%(n=1470)$ were women. The prevalence of frailty by age and gender is shown in Table 2. The overall prevalence of pre-frailty and frailty was 39.5 and $16.9 \%$, respectively. The prevalence of frailty increased with age, being $14.6 \%$ for respondents aged $60-64$ years and $26.5 \%$ for those aged 75 years and older $(P$ trend of $<0.001$ ).

\section{Individual correlates of frailty}

The individual characteristics of older people and factors associated with the presence of frailty are shown in Table 3. Overall, the univariate analysis showed that the majority of individual factors were associated with frailty except for gender, smoking and organization participation.

Further multivariate analysis indicated that after adjusting for both age and/or gender, the trend of frailty increasing with age remained (adjusted $P<0.001$ ). The prevalence of frailty was not different between genders in the univariate analysis $(P=0.063)$, but after adjusting for age, the analysis showed that frailty prevalence was higher among women $(\mathrm{OR}=1.17,95 \% \mathrm{CI}=1.01-1.36$, adjusted $P=0.039$ ). Those who had a higher educational level had half the risk of frailty compared with those who were illiterate. The associations between marital status and work status and frailty disappeared after adjustment for age and gender.

Among lifestyle factors, after adjusting for both age and gender, smoking was not associated with frailty, and those who were assessed as having alcohol dependence had more frailty than nondrinkers $(\mathrm{OR}=1.84,95 \% \mathrm{CI}=$ $1.33-2.55$, adjusted $P<0.001)$. An increased level of MIPA was associated with a reduced risk of frailty (high compared to none: $\mathrm{OR}=0.52,95 \% \mathrm{CI}=0.43-0.64$, adjusted $P<0.001$; low compared to none: $\mathrm{OR}=0.74$, $95 \% \mathrm{CI}=0.63-0.88$, adjusted $P=0.001)$. No association was observed between organization participation and frailty.

Both SRH and PWB were significantly associated with frailty after adjustment for age and gender. Those who rated their health as poor had a significant increased risk of frailty $(\mathrm{OR}=3.16,95 \% \mathrm{CI}=2.70-3.68$, adjusted $P<$ 0.001) compared with those who rated their health as good. Those who were considered to have a psychological disorder also had a significant increased risk of frailty $(\mathrm{OR}=3.69,95 \% \mathrm{CI}=2.88-4.72$, adjusted $P<0.001)$ compared with those who were not.

\section{Environmental correlates of frailty}

Before any independent variables were added to the model, it indicated that there was a statistical significantly variation in frailty across neighbourhoods $(\mathrm{x} 2=134.91, P$ $<0.001$ ). The interclass correlation coefficient (ICC) was 0.127 , indicating that $12.7 \%$ of the variance in the prevalence of frailty was attributable to neighbourhood-level grouping.

The results of the multilevel model of frailty are presented in Table 4. With only individual-level environmental variables adding to the model (Model 1), it indicated negative associations between individual-level AQ and individual-level SP and frailty. For instance, compared to respondents who perceived their neighbourhood's AQ as being in the first quartile, the OR of frailty for those in the fourth quartile was $0.65(95 \% \mathrm{CI}$ : $0.47-0.89)$. However, with only neighbourhood-level environmental variables adding to the model (Model 2), it indicated that there were no significant associations between the four neighbourhood-level environmental characteristics and frailty.

With controlling for individual covariates, and both individual-level and neighbourhood-level variables were

Table 2 The Prevalence of Robust, Pre-frail and Frail among Older People by Gender and Age Groups ( $N=2559)$

\begin{tabular}{|c|c|c|c|c|c|c|c|}
\hline \multirow[t]{2}{*}{ Frailty status } & \multirow[t]{2}{*}{ Gender } & \multicolumn{5}{|c|}{ Age Group, n (\%) } & \multirow[t]{2}{*}{$P$ trend } \\
\hline & & $60-64 y$ & $65-69 y$ & $70-74 y$ & $\geq 75 y$ & All Ages & \\
\hline & Both Gen & & & & & & \\
\hline Robust (0) & & $545(49.2)$ & $369(41.1)$ & $153(34.9)$ & $47(40.2)$ & $1114(43.5)$ & \\
\hline Pre-frail (1-2) & & $400(36.1)$ & $382(42.6)$ & 191 (43.6) & 39 (33.3) & $1012(39.5)$ & \\
\hline \multirow[t]{2}{*}{ Frail $(\geq 3)$} & & $162(14.6)$ & $146(16.3)$ & $94(21.5)$ & $31(26.5)$ & $433(16.9)$ & $<0.001$ \\
\hline & Man & & & & & & \\
\hline Robust (0) & & $225(52.2)$ & 178 (52.2) & $73(36.0)$ & 25 (39.7) & $501(46.0)$ & \\
\hline Pre-frail (1-2) & & $144(33.4)$ & $157(40.1)$ & $86(42.4)$ & $17(27.0)$ & $404(37.1)$ & \\
\hline \multirow[t]{2}{*}{ Frail $(\geq 3)$} & & $62(14.4)$ & $57(14.5)$ & $44(21.7)$ & $21(33.3)$ & $184(16.9)$ & $<0.001$ \\
\hline & Woman & & & & & & \\
\hline Robust (0) & & $320(47.3)$ & 191 (37.8) & $80(34.0)$ & $22(40.7)$ & $613(41.7)$ & \\
\hline Pre-frail (1-2) & & $256(37.9)$ & 225 (44.6) & $105(44.7)$ & $22(40.7)$ & 608 (41.4) & \\
\hline Frail $(\geq 3)$ & & $100(14.8)$ & 89 (17.6) & $50(21.3)$ & $10(18.5)$ & 249 (16.9) & $<0.001$ \\
\hline
\end{tabular}


Table 3 Individual Factors associated with Frailty among Older People ( $\mathrm{N}=2559)$

\begin{tabular}{|c|c|c|c|c|c|c|c|c|}
\hline \multirow[t]{2}{*}{ Variable } & \multicolumn{5}{|c|}{ Mean \pm SD/ n (\%) } & \multicolumn{3}{|c|}{ Age- and Gender-adjusted } \\
\hline & Overall & Robust & Pre-frail & Frail & $P$ & $\mathrm{OR}$ & $95 \% \mathrm{Cl}$ & $P$ \\
\hline Age, year & $66.12 \pm 4.85$ & $65.53 \pm 4.70$ & $66.34 \pm 4.64$ & $67.16 \pm 5.49$ & $<0.001$ & 1.05 & $1.04-1.07$ & $<0.001^{\mathrm{e}}$ \\
\hline Gender & & & & & 0.063 & & & \\
\hline Man & $1089(42.6)$ & $501(46.0)$ & $404(37.1)$ & $184(16.9)$ & & 1.00 & & \\
\hline Woman & $1470(57.4)$ & $613(41.7)$ & $608(41.4)$ & $249(16.9)$ & & 1.17 & $1.01-1.36$ & $0.039^{f}$ \\
\hline Education & & & & & $<0.001$ & & & \\
\hline Illiteracy & $98(3.8)$ & $25(25.5)$ & $43(43.9)$ & $30(30.6)$ & & 1.00 & & \\
\hline Primary school & $397(15.5)$ & $177(44.6)$ & $144(36.3)$ & $76(19.1)$ & & 0.51 & $0.34-0.78$ & 0.002 \\
\hline Junior high school & $1006(39.3)$ & $445(44.2)$ & $383(38.1)$ & $178(17.7)$ & & 0.54 & $0.36-0.79$ & 0.002 \\
\hline Senior high school & $709(27.7)$ & $325(45.8)$ & $286(40.3)$ & $98(13.8)$ & & 0.47 & $0.31-0.69$ & $<0.001$ \\
\hline University & $349(13.6)$ & $142(40.7)$ & $156(44.7)$ & $51(14.6)$ & & 0.52 & $0.34-0.79$ & 0.002 \\
\hline Work status & & & & & 0.001 & & & \\
\hline Employed & $331(12.9)$ & $169(51.1)$ & 99 (29.9) & $63(19.0)$ & & 0.85 & $0.69-1.06$ & 0.146 \\
\hline Other ${ }^{a}$ & $2228(87.1)$ & $945(42.4)$ & $913(41.0)$ & $370(16.6)$ & & 1.00 & & \\
\hline Marital status & & & & & 0.001 & & & \\
\hline Married & 2269 (88.7) & $1001(44.1)$ & 906 (39.9) & $362(16.0)$ & & 0.80 & $0.63-1.00$ & 0.051 \\
\hline Other $^{\mathrm{b}}$ & $290(11.3)$ & $113(39.0)$ & 106 (36.6) & $71(24.5)$ & & 1.00 & & \\
\hline Smoking & & & & & 0.410 & & & \\
\hline Nonsmoker & $2070(80.9)$ & $894(43.2)$ & 815 (39.4) & $361(17.4)$ & & 1.00 & & \\
\hline Ex-smoker & $81(3.2)$ & $33(40.7)$ & $32(39.5)$ & 16 (19.8) & & 1.20 & $0.78-1.83$ & 0.407 \\
\hline Current Smoker & 408 (15.9) & $187(45.8)$ & 165 (40.4) & $56(13.7)$ & & 0.99 & $0.79-1.24$ & 0.925 \\
\hline Drinking & & & & & 0.001 & & & \\
\hline Nondrinker & $2057(80.4)$ & $902(43.9)$ & $822(40.0)$ & $333(16.2)$ & & 1.00 & & \\
\hline Drinker & $359(14.0)$ & $157(43.7)$ & $145(40.4)$ & $57(15.9)$ & & 1.13 & $0.90-1.41$ & 0.289 \\
\hline Alcohol Dependence & $143(5.6)$ & $55(38.5)$ & $45(31.5)$ & $43(30.1)$ & & 1.84 & $1.33-2.55$ & $<0.001$ \\
\hline MIPA level & & & & & $<0.001$ & & & \\
\hline None & $753(29.4)$ & $279(37.1)$ & 306 (40.6) & $168(22.3)$ & & 1.00 & & \\
\hline Low & 1199 (46.9) & $520(43.4)$ & $480(40.0)$ & 199 (16.6) & & 0.74 & $0.63-0.88$ & 0.001 \\
\hline High & $607(23.7)$ & $315(51.9)$ & $226(37.2)$ & $66(10.9)$ & & 0.52 & $0.43-0.64$ & $<0.001$ \\
\hline Organization Participation & & & & & 0.241 & & & \\
\hline Yes & $1689(66.0)$ & 739 (43.8) & $679(40.2)$ & $271(16.0)$ & & 0.89 & $0.76-1.04$ & 0.136 \\
\hline No & $870(34.0)$ & $375(43.1)$ & $333(38.3)$ & 162 (18.6) & & 1.00 & & \\
\hline Self-Rated Health & & & & & $<0.001$ & & & \\
\hline Good & $1452(56.7)$ & $803(55.3)$ & $512(35.3)$ & $137(9.4)$ & & 1.00 & & \\
\hline Poor & $1107(43.3)$ & $311(28.1)$ & $500(45.2)$ & $296(26.7)$ & & 3.16 & $2.70-3.68$ & $<0.001$ \\
\hline WHO-5', score & $18.82 \pm 4.35$ & $20.14 \pm 3.56$ & $18.37 \pm 4.41$ & $16.47 \pm 4.82$ & $<0.001$ & 0.87 & $0.86-0.89$ & $<0.001$ \\
\hline Psychological Disorder ${ }^{c, d}$ & & & & & $<0.001$ & & & \\
\hline yes & $258(10.1)$ & $38(14.7)$ & $127(49.2)$ & $93(36.0)$ & & 3.69 & $2.88-4.72$ & $<0.001$ \\
\hline no & $2295(89.7)$ & $1072(46.7)$ & 885 (38.6) & $338(14.7)$ & & 1.00 & & \\
\hline
\end{tabular}

SD standard deviation, MIPA moderate intensity physical activity

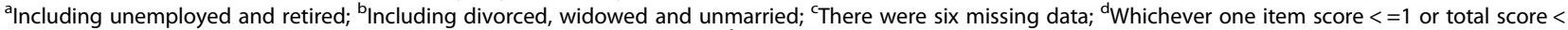

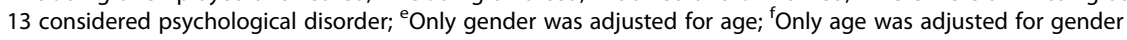

added to the final model (Model 3), which showed the similar results. Individual-level AQ, individual-level SC, individual-level SP, and neighbourhood-level WE were negatively associated with frailty. Specifically speaking, compared to respondents who perceived the AQ and SC of their neighbourhood to be in the first quartile, the 
Table 4 The Odds Ratios for Frailty associated with Environmental Characteristics $(N=2154)$

\begin{tabular}{|c|c|c|c|c|c|c|c|c|c|}
\hline \multirow[t]{2}{*}{ Variable } & \multicolumn{3}{|c|}{ Model 1} & \multicolumn{3}{|c|}{ Model 2} & \multicolumn{3}{|c|}{ Model $3^{\text {a }}$} \\
\hline & $\mathrm{OR}$ & $95 \% \mathrm{Cl}$ & P & $\mathrm{OR}$ & $95 \% \mathrm{Cl}$ & $P$ & $\mathrm{OR}$ & $95 \% \mathrm{Cl}$ & P \\
\hline \multicolumn{10}{|l|}{ Fixed effects } \\
\hline \multicolumn{10}{|c|}{ Individual-level environment characteristics } \\
\hline \multicolumn{10}{|c|}{ Aesthetic Quality } \\
\hline 1st quartile & 1.00 & & & & & & 1.00 & & \\
\hline 2nd quartile & 0.79 & $0.61-1.03$ & 0.077 & & & & 0.78 & $0.60-1.02$ & 0.070 \\
\hline 3rd quartile & 0.79 & $0.60-1.04$ & 0.093 & & & & 0.78 & $0.59-1.02$ & 0.074 \\
\hline 4th quartile & 0.65 & $0.47-0.89$ & 0.008 & & & & 0.65 & $0.47-0.89$ & 0.008 \\
\hline \multicolumn{10}{|c|}{ Walking Environment } \\
\hline 1st quartile & 1.00 & & & & & & 1.00 & & \\
\hline 2nd quartile & 1.12 & $0.86-1.47$ & 0.394 & & & & 1.15 & $0.88-1.51$ & 0.310 \\
\hline 3rd quartile & 1.21 & $0.92-1.59$ & 0.170 & & & & 1.29 & $0.97-1.70$ & 0.075 \\
\hline 4th quartile & 1.13 & $0.82-1.55$ & 0.451 & & & & 1.22 & $0.89-1.67$ & 0.225 \\
\hline \multicolumn{10}{|l|}{ Social Cohesion } \\
\hline 1st quartile & 1.00 & & & & & & 1.00 & & \\
\hline 2nd quartile & 1.02 & $0.79-1.33$ & 0.863 & & & & 0.98 & $0.75-1.28$ & 0.888 \\
\hline 3rd quartile & 0.91 & $0.69-1.19$ & 0.485 & & & & 0.86 & $0.66-1.14$ & 0.291 \\
\hline 4th quartile & 0.76 & $0.56-1.02$ & 0.069 & & & & 0.73 & $0.54-0.99$ & 0.043 \\
\hline \multicolumn{10}{|c|}{ Social Participation } \\
\hline 1st quartile & 1.00 & & & & & & 1.00 & & \\
\hline 2nd quartile & 0.76 & $0.59-0.96$ & 0.025 & & & & 0.76 & $0.59-0.97$ & 0.028 \\
\hline 3rd quartile & 0.60 & $0.47-0.78$ & $<0.001$ & & & & 0.59 & $0.45-0.77$ & $<0.001$ \\
\hline 4th quartile & 0.61 & $0.47-0.80$ & $<0.001$ & & & & 0.59 & $0.45-0.77$ & $<0.001$ \\
\hline \multicolumn{10}{|c|}{ Neighborhood-level environment characteristics } \\
\hline \multicolumn{10}{|l|}{ Aesthetic Quality } \\
\hline 1st quartile & & & & 1.00 & & & 1.00 & & \\
\hline 2nd quartile & & & & 1.36 & $0.68-2.73$ & 0.388 & 1.37 & $0.69-2.71$ & 0.367 \\
\hline 3rd quartile & & & & 1.05 & $0.52-2.13$ & 0.884 & 1.16 & $0.58-2.32$ & 0.675 \\
\hline 4th quartile & & & & 1.32 & $0.58-2.97$ & 0.506 & 1.61 & $0.72-3.61$ & 0.243 \\
\hline \multicolumn{10}{|c|}{ Walking Environment } \\
\hline 1st quartile & & & & 1.00 & & & 1.00 & & \\
\hline 2nd quartile & & & & 1.02 & $0.48-2.12$ & 0.974 & 0.97 & $0.47-2.01$ & 0.945 \\
\hline 3rd quartile & & & & 0.86 & $0.42-1.79$ & 0.693 & 0.81 & $0.39-1.66$ & 0.561 \\
\hline 4th quartile & & & & 0.48 & $0.21-1.07$ & 0.073 & 0.43 & $0.19-0.95$ & 0.036 \\
\hline \multicolumn{10}{|l|}{ Social Cohesion } \\
\hline 1st quartile & & & & 1.00 & & & 1.00 & & \\
\hline 2nd quartile & & & & 1.14 & $0.62-2.09$ & 0.677 & 1.18 & $0.65-2.13$ & 0.593 \\
\hline 3rd quartile & & & & 1.14 & $0.64-2.02$ & 0.653 & 1.17 & $0.67-2.04$ & 0.582 \\
\hline 4th quartile & & & & 0.63 & $0.32-1.24$ & 0.181 & 0.73 & $0.37-1.42$ & 0.355 \\
\hline \multicolumn{10}{|c|}{ Social Participation } \\
\hline 1st quartile & & & & 1.00 & & & 1.00 & & \\
\hline 2nd quartile & & & & 0.67 & $0.39-1.14$ & 0.140 & 0.80 & $0.46-1.38$ & 0.418 \\
\hline 3rd quartile & & & & 0.78 & $0.47-1.32$ & 0.359 & 1.00 & $0.60-1.68$ & 0.994 \\
\hline 4th quartile & & & & 0.92 & $0.52-1.65$ & 0.784 & 1.30 & $0.72-2.34$ & 0.384 \\
\hline
\end{tabular}


Table 4 The Odds Ratios for Frailty associated with Environmental Characteristics ( $N=2154)$ (Continued)

\begin{tabular}{|c|c|c|c|c|c|c|c|c|c|}
\hline \multirow[t]{2}{*}{ Variable } & \multicolumn{3}{|c|}{ Model 1} & \multicolumn{3}{|c|}{ Model 2} & \multicolumn{3}{|c|}{ Model $3^{\text {a }}$} \\
\hline & $\mathrm{OR}$ & $95 \% \mathrm{Cl}$ & $P$ & OR & $95 \% \mathrm{Cl}$ & $P$ & OR & $95 \% \mathrm{Cl}$ & P \\
\hline \multicolumn{10}{|l|}{ Random effects } \\
\hline Neighborhood-level variance (SE) & \multicolumn{3}{|c|}{$0.38(0.11)$} & \multicolumn{3}{|c|}{$0.24(0.07)$} & \multicolumn{3}{|c|}{$0.22(0.07)$} \\
\hline \multicolumn{10}{|l|}{ Model fit } \\
\hline$-2 \mathrm{LL}$ & \multicolumn{3}{|c|}{4230.3178} & \multicolumn{3}{|c|}{4246.6448} & \multicolumn{3}{|c|}{4149.2458} \\
\hline $\mathrm{AIC}$ & \multicolumn{3}{|c|}{4260.3180} & \multicolumn{3}{|c|}{4276.6450} & \multicolumn{3}{|c|}{4227.2460} \\
\hline
\end{tabular}

${ }^{a}$ gender, age, education, marital status, work status, smoking, and drinking were adjusted

ORs of frailty for those in the fourth quartile were 0.65 (95\%CI: 0.47-0.89) and 0.73 (95\%CI: 0.54-0.99), respectively. Compared to respondents in the first quartile of SP, the ORs of frailty for those in the second, third and fourth quartiles of SP were 0.76 (95\%CI: 0.59-0.97), 0.59 (95\%CI: 0.45-0.77) and 0.59 (95\%CI: 0.45-0.77), respectively. Compared to the WE of neighbourhoods in the first quartile, the OR of frailty for those in the fourth quartile was 0.43 (95\%CI: 0.19-0.95).

\section{Discussion}

The findings of this study showed that the prevalence of frailty among community-dwelling older people in the current sample was similar to previous studies that used the same tool $[29,33]$. Plenty of studies have shown that frailty increases with age [2], which was also shown in the current study. Frailty reflects a dynamic health condition; to understand the prevalence and correlates of frailty are important for prevention and intervention policies. This study also indicated that the prevalence of frailty was higher among women and those with a lower educational level, lower moderate intensity physical activity, and poor self-rated health, which is consistent with previous studies [3, 9, 34]. Furthermore, this study provided some different results regarding the risk factors of frailty. Alcohol consumption was associated with many health conditions, but the impact on frailty was absent. Those who are alcohol dependent might not just have a high alcohol consumption; more importantly is the influence on their spirit. Depressive syndrome has had a significant influence on frailty in the previous literature $[35,36]$, and we found that the influence of psychological well-being on the level of frailty should not be overlooked.

The present study showed the relationship between the physical and social environmental characteristics of the neighbourhood and frailty among community-dwelling older people in Shanghai, China. The final model showed that the individual-level AQ and neighbourhood-level WE of the neighbourhood were negatively associated with frailty by adjusting for individual covariates. Malnutrition (both undernutrition and obesity) plays a key role in the pathogenesis of frailty [37]. The aesthetic quality of the neighbourhood environment has been shown to affect health behaviours such as improving fruit and vegetable consumption, which is an essential component of a healthy diet and one of the most modifiable risk factors for chronic disease [12]. In addition, neighbourhood aesthetics and walking environment were correlated with obesity and body mass index (BMI) [13, 38]. Even more, a high aesthetic quality of the neighbourhood probably improves residents' pleasant mood, and was related to a higher mental well-being [22, 39] and lower depressive symptoms [40]. The walkability of the neighbourhood refers to walkable roads, access to facilities and opportunities for activities, which are correlated with various types of physical activity [13, 23] and chronic diseases [41, 42]. Older people living in a more walkable neighbourhood seem to have more opportunities to get out and interact with others, even residents with mobility impairment [13].

Our study showed that individual-level SC and individual-level SP were negatively associated with frailty. A previous study found that in community-dwelling older people, a stronger sense of social cohesion (refers to trust and interaction with neighbours) seemed to protect against frailty [25]. In our study, SC was measured by helping neighbours, getting along with each other, trust, and sharing the same values. People who perceived their neighbourhoods as more cohesive might be more likely to improve the positive social norms regarding healthy behaviours and social support. Neighbours who trust each other are more likely to provide help with promoting access to services and amenities in daily life. A systematic review highlighted that social participation had more consistent results than other social environmental characteristics for predicting frailty [24]. Not like SC, which refers to inter-related features of society, SP focus more on individual participation in several social activities within daily life. In China, most older adults retire at retirement age or do not have a formal job beforehand, and becoming involved in neighbourhood activities is very common for them. Previous studies found a relationship between social participation (frequent group engagement, attending a religious service, physical leisure activities, participation in helping other people) and lower frailty [43, 44]; and another study 
also showed evidence that both individual-level and community-level sports group participation and individual-level hobby group participation were positively correlated with physical and mental health among older adults $[11,45]$. In the current study, SP included eight types of participation. To be specific, these neighbourhood social activities involved helping manage chronic diseases, accessing health knowledge, increasing physical activities and promoting interpersonal relationships, which are all in favour of health. Those who were more likely to participate in those activities regularly gained more health benefits.

There are some limitations to our study. First, the cross-sectional study design could not define the direction of causality. Second, neighbourhood-level environmental characteristics were measured by self-reported questionnaires rather than objective measures, and therefore cannot represent the true conditions of the neighbourhood environment. In the future, a longitudinal study with an objective neighbourhood environmental characteristics measurement, more balanced and representative samples and that controls for more confounding variables (for example socio-economic characteristics) should be conducted to explain the relationships between individual factors and neighbourhood environmental characteristics and frailty among community-dwelling older people.

\section{Conclusions}

This study indicates that frailty is a highly prevalent health condition among the aged population in China. Both individual factors and environmental characteristics of the neighbourhood are associated with frailty among Chinese community-dwelling older people. Primary healthcare should pay more attention to those who are older age, women, those with a low educational level, and those with mental health problems among the frail elderly. It is important to encourage healthy behaviours and social participation; meanwhile, building aesthetic, walkable and cohesive neighbourhoods may decrease frailty among Chinese community-dwelling older people.

\section{Additional file}

Additional file 1: The dataset of analysis. The dataset of analysis comes from a subsample of the Shanghai Healthy City Survey (Round 5). It includes the total complete data (2559 elders) in Sheet 1 and the processed data for multilevel analysis (2154 elders) in Sheet 2. (XLSX 1262 kb)

\footnotetext{
Abbreviations

-2LL: -2 log likelihood; AIC: Akaike information criterion; ANOVA: Analysis of variance; AQ: Aesthetic quality; BMI: Body mass index; CAGE: Cut down, Annoyed, Guilty, Eye opener; Cl: Confidence interval; Fl: Frailty index; FP: Frailty phenotypes; FRAIL: Fatigue, Resistance, Ambulation, Illness, Loss of weight; MIPA: Moderate intensity physical activity; OR: Odds ratio; SC: Social cohesion; SD: Standard deviation; SE: Standard error; SP: Social participation;
}

SPSS: Statistical Package for the Social Sciences; WE: Walking environment; WHO: World Health Organization

\section{Acknowledgements}

We appreciate all the community health workers for their contribution to the investigation and the students from the School of Public Health at Fudan

University for their contribution to data entry. Lastly, thanks for the editors from

Nature Research Editing Service with their contribution to polishing the language.

\section{Funding}

The National Natural Science Foundation of China (Grant Number 71490735), and the National Key R\&D Program of China (Grant Number

2018YFC2002000) supported this study.

Availability of data and materials

The data applied and analysed in the current study are available from the corresponding author upon reasonable request.

\section{Authors' contributions}

BY participated in the study design, performed the survey and the statistical analysis, and drafted and revised the manuscript. JG proposed the study, participated in the study design, performed the survey, and guided the revision of the manuscript. HF proposed the study, participated in the study design, and guided the revision of the manuscript. All authors read and approved the final manuscript.

Ethics approval and consent to participate

Ethical approval was obtained from the Ethics Committee for Medical Research at the School of Public Health, Fudan University. All participants provided written consent to participate.

Consent for publication

Not applicable.

Competing interests

The authors declare that they have no competing interests.

\section{Publisher's Note}

Springer Nature remains neutral with regard to jurisdictional claims in published maps and institutional affiliations.

\section{Author details}

${ }^{1}$ School of Public Health, Fudan University, Shanghai, China. ${ }^{2}$ Fudan Health Communication Institute, School of Public Health, Fudan University, PO Box 248, 138 Yixueyuan Road, Shanghai 200032, China.

Received: 12 June 2018 Accepted: 14 November 2018

Published online: 14 December 2018

\section{References}

1. Morley JE, Vellas B, Abellan Van Kan G, Anker SD, Bauer JM, Bernabei R, Cesari M, Chumlea WC, Doehner W, Evans J, et al. Frailty consensus: a call to action. J Am Med Dir Assoc. 2013;14(6):392-7.

2. Clegg A, Young J, lliffe S, Rikkert MO, Rockwood K. Frailty in elderly people. LANCET. 2013;381(9868):752-62.

3. Dent E, Lien C, Lim WS, Wong WC, Wong CH, Ng TP, Woo J, Dong B, de la Vega S, Hua Poi PJ, et al. The Asia-Pacific clinical practice guidelines for the Management of Frailty. J Am Med Dir Assoc. 2017;18(7):564-75

4. Cesari M, Prince M, Thiyagarajan JA, De Carvalho IA, Bernabei R, Chan P, Gutierrez-Robledo LM, Michel J, Morley JE, Ong P, et al. Frailty: an emerging public health priority. J Am Med Dir Assoc. 2016;17(3):188-92.

5. Liu L, Lee W, Chen L, Hwang A, Lin M, Peng L, Chen L. Association between frailty, osteoporosis, falls and hip fractures among community-dwelling people aged 50 years and older in Taiwan: results from I-Lan longitudinal aging study. PLoS One. 2015;10(9):e136968. https://doi.org/10.1371/journal. pone.0136968 Published online 2015 Sep 8.

6. World Report on Ageing and Health. Geneva: World Health Organization. [http://www.who.int/ageing/events/world-report-2015-launch/en/]. Accessed 14 Oct 2018

7. Dent E, Kowal P, Hoogendijk EO. Frailty measurement in research and clinical practice: a review. EUR J INTERN MED. 2016;31(1):3-10. 
8. Heuberger RA. The frailty syndrome: a comprehensive review. Journal of Nutrition in Gerontology and Geriatrics. 2011;30(4):315-68.

9. Woo J, Zheng Z, Leung J, Chan P. Prevalence of frailty and contributory factors in three Chinese populations with different socioeconomic and healthcare characteristics. BMC Geriatr. 2015;15(1):1-11.

10. Hoogendijk EO, van Hout HPJ, Heymans MW, van der Horst HE, Frijters DHM, Broese Van Groenou MI, Deeg DJH, Huisman M. Explaining the association between educational level and frailty in older adults: results from a 13-year longitudinal study in the Netherlands. Ann Epidemiol. 2014; 24(7):538-44.

11. Kanamori S, Kai Y, Aida J, Kondo K, Kawachi I, Hirai H, Shirai K, Ishikawa Y, Suzuki $K$, Group TJ. Social participation and the prevention of functional disability in older Japanese: the JAGES cohort study. PLoS One. 2014;9(6):e99638.

12. Litt JS, Soobader MJ, Turbin MS, Hale JW, Buchenau M, Marshall JA. The influence of social involvement, neighborhood aesthetics, and community garden participation on fruit and vegetable consumption. Am J Public Health. 2011;101(8):1466-73.

13. King AC, Sallis JF, Frank LD, Saelens BE, Cain K, Conway TL, Chapman JE, Ahn DK, Kerr J. Aging in neighborhoods differing in walkability and income: associations with physical activity and obesity in older adults. Soc Sci Med. 2011;73(10):1525-33.

14. Wahl HW, Oswald F. Chapter 8: environmental perspectives on aging. The SAGE Handbook of Social Gerontology. 2010:111-24. https://doi.org/10. 4135/9781446200933.n8.

15. Raphael D, Cava M, Brown I, Renwick R, Heathcote K, Weir N, Wright K Kirwan L. Frailty: a public health perspective. Canadian journal of public health. 1995;86(4):224-7.

16. Beard JR, Officer A, de Carvalho IA, Sadana R, Pot AM, Michel J, LloydSherlock P, Epping-Jordan JE, Peeters GMEE, Mahanani WR, et al. The world report on ageing and health: a policy framework for healthy ageing. Lancet. 2016;387(10033):2145-54

17. Cesari M, Vellas B, Hsu FC, Newman AB, Doss H, King AC, Manini TM, Church T, Gill TM, Miller ME, et al. A physical activity intervention to treat the frailty syndrome in older persons--results from the LIFE-P study. J Gerontol Ser A Biol Med Sci. 2015;70(2):216-22.

18. Good health adds life to years - Global brief for World Health Day 2012. Geneva: World Health Organization. [http://www.who.int/ageing/ publications/whd2012_global_brief/en/]. Accessed 14 Oct 2018.

19. Shanghai bureau of statistics: the present situation and forecast for aging population in shanghai. [http://www.stats-sh.gov.cn/html/fxbg/201805/ 1002033.html]. Accessed 14 Oct 2018.

20. Elliott J, Gale CR, Parsons S, Kuh D. Neighbourhood cohesion and mental wellbeing among older adults: a mixed methods approach. Soc Sci Med. 2014;107(2):44-51.

21. Nordin S, McKee K, Wijk H, Elf M. The association between the physical environment and the well-being of older people in residential care facilities: a multilevel analysis. J Adv Nurs. 2017;73(12):2942-52

22. Gao J, Weaver SR, Fu H, Jia Y, Li J. Relationships between neighborhood attributes and subjective well-being among the Chinese elderly: data from Shanghai. BIOSCI TRENDS. 2017;11(5):516-23.

23. Gao J, Fu H, Li J, Jia Y. Association between social and built environments and leisure-time physical activity among Chinese older adults - a multilevel analysis. BMC Public Health. 2015;15(1):1-11.

24. Duppen D, Van der Elst MCJ, Dury S, Lambotte D, De Donder L. The social Environment's relationship with frailty. J Appl Gerontol. 2017. https://doi. org/10.1177/0733464816688310.

25. Cramm JM, Nieboer AP. Relationships between frailty, neighborhood security, social cohesion and sense of belonging among communitydwelling older people. Geriatr Gerontol Int. 2013;13(3):759-63.

26. Administrative divisions of China. [https://en.wikipedia.org/wiki/ Administrative_divisions_of_China]. Accessed 14 Oct 2018.

27. Morley JE, Malmstrom TK, Miller DK. A simple frailty questionnaire (FRAIL) predicts outcomes in middle aged African Americans. J Nutr Health Aging. 2012;16(7):601-8.

28. Kojima G. Frailty defined by FRAIL scale as a predictor of mortality: a systematic review and meta-analysis. J Am Med Dir Assoc. 2018;19(6):480-3.

29. Woo J, Yu R, Wong M, Yeung F, Wong M, Lum C. Frailty screening in the community using the FRAIL scale. J Am Med Dir Assoc. 2015;16(5):412-9.

30. Mujahid MS, Diez RA, Morenoff JD, Raghunathan T. Assessing the measurement properties of neighborhood scales: from psychometrics to ecometrics. Am J Epidemiol. 2007;165(8):858-67.
31. Mayfield D, McLeod G, Hall P. The CAGE questionnaire: validation of a new alcoholism screening instrument. Am J Psychiatry. 1974;131(10):1121-3 [http://psycnet.apa.org/record/1975-03394-001].

32. WHO5_Chinese_PR. [https://www.psykiatri-regionh.dk/who-5/Documents/ WHO5_Chinese_PR.pdf]. Accessed 14 Oct 2018.

33. Jung HW, Jang IY, Lee YS, Lee CK, Cho El, Kang WY, Chae JH, Lee EJ, Kim $\mathrm{DH}$. Prevalence of frailty and aging-related health conditions in older Koreans in rural communities: a cross-sectional analysis of the aging study of Pyeongchang rural area. J Korean Med Sci. 2016;31(3):345-52.

34. Zheng Z, Guan S, Ding H, Wang Z, Zhang J, Zhao J, Ma J, Chan P. Prevalence and incidence of frailty in community-dwelling older people: Beijing longitudinal study of aging II. J Am Geriatr Soc. 2016;64(6):1281-6.

35. Bilotta C, Casè A, Nicolini P, Mauri S, Castelli M, Vergani C. Social vulnerability, mental health and correlates of frailty in older outpatients living alone in the community in Italy. Aging Ment Health. 2010;14(8):1024-36.

36. Fried LP, Tangen CM, Walston J, Newman AB, Hirsch C, Gottdiener J, Seeman T, Tracy R, Kop WJ, Burke G, et al. Frailty in older adults: evidence for a phenotype. J Gerontol A Biol Sci Med Sci. 2001;56(3):M146-56.

37. Cruz-Jentoft AJ, Kiesswetter E, Drey M, Sieber CC. Nutrition, frailty, and sarcopenia. Aging Clin Exp Res. 2017;29(1):43-8.

38. Boehmer TK, Hoehner CM, Deshpande AD, Brennan RL, Brownson RC. Perceived and observed neighborhood indicators of obesity among urban adults. Int J Obes. 2007;31(6):968-77.

39. Bond L, Kearns A, Mason P, Tannahill C, Egan M, Whitely E. Exploring the relationships between housing, neighbourhoods and mental wellbeing for residents of deprived areas. BMC Public Health. 2012;12:48.

40. Mair C, Diez RA, Shen M, Shea S, Seeman T, Echeverria S, O'Meara ES. Crosssectional and longitudinal associations of neighborhood cohesion and stressors with depressive symptoms in the multiethnic study of atherosclerosis. Ann Epidemiol. 2009;19(1):49-57.

41. Unger E, Diez-Roux AV, Lloyd-Jones DM, Mujahid MS, Nettleton JA, Bertoni A, Badon SE, Ning H, Allen NB. Association of neighborhood characteristics with cardiovascular health in the multi-ethnic study of atherosclerosis. Circ Cardiovasc Qual Outcomes. 2014;7(4):524-31.

42. Mujahid MS, Diez RA, Morenoff JD, Raghunathan TE, Cooper RS, Ni H, Shea S. Neighborhood characteristics and hypertension. EPIDEMIOLOGY. 2008; 19(4):590-8.

43. Andrew MK, Keefe JM. Social vulnerability from a social ecology perspective: a cohort study of older adults from the National Population Health Survey of Canada. BMC Geriatr. 2014;14(1):1-14.

44. Woo J, Goggins W, Sham A, Ho SC. Social determinants of frailty. GERONTOLOGY. 2005:51(6):402-8.

45. Tsuji T, Miyaguni Y, Kanamori S, Hanazato M, Kondo K. Community-level sports group participation and older individuals' depressive symptoms. Med Sci Sports Exerc. 2018;50(6):1199-205.

Ready to submit your research? Choose BMC and benefit from:

- fast, convenient online submission

- thorough peer review by experienced researchers in your field

- rapid publication on acceptance

- support for research data, including large and complex data types

- gold Open Access which fosters wider collaboration and increased citations

- maximum visibility for your research: over $100 \mathrm{M}$ website views per year

At $\mathrm{BMC}$, research is always in progress.

Learn more biomedcentral.com/submission 